\title{
Kepuasan Jamaah Masjid Haji Agus Salim Terhadap Sound Sistem Yang Terpasang
}

\author{
Azam Muzakhim Imammudin ${ }^{1}$, Farida Arinie Soelistianto ${ }^{2}$, Waluyo $^{3}$, Hudiono ${ }^{4}$, \\ Koesmarijanto ${ }^{5}$ \\ 1,2,3,4,5 Jurusan Teknik Elektro, Politeknik Negeri Malang
}

\begin{abstract}
Abstrak
Indonesia merupakan negara muslim terbesar di dunia, dengan jumlah 264 juta pendudukyang tersebar di berbagai pulau. Dengan mayoritas penduduk Indonesia yang beragama muslim maka jumlah tempat peribadatan atau masjid jumlahnya sebanding dengan penduduknya. Saat ini terdapat sekitar 250 ribu masjid dan 550 ribu mushala. Namun dari jumlah tersebut tercatat ribuan masjid masih mempunyai peralatan dan penataan sistem tata suara yang buruk. Masjid Haji Agus Salim yang ada di jalan piranha atas kota malang termasuk dalam kategori mempunyai kualitas suara yang buruk. Pada pengabdian ini diusulkan pelatihan penataan dan instalasi sistem tata suara di Masjid Haji Agus Salim kota malang. Diharapkan dengan adanya pelatihan dan penataan sistem tata suara ini kualitas suara yang dihasilkan semakin bagus sehingga membuat nyaman masyarakat yang ingin beribadah. Hasil dari pelatihan ini menunjukkan bahwa sebanyak 20 jamaah masjid merasa sangat puas dengan tata suara yang ada di masjid haji agus salim.
\end{abstract}

Keywords - pelatihan, tata suara, masjid haji agus salim

\section{PENDAHULUAN}

$\mathrm{S}$ aat ini di Indonesia terdapat 250 ribu masjid dan 550 ribu mushalla, jumlah bangunan tersebut merupakan jumlah terbanyak di seluruh dunia. Namun ada ribuan masjid di Indonesia yang dinyatakan tidak mempunyai peralatan sistem pengeras suara yang mumpuni. Suara Adzan dan khotbah yang terdengar dinilai pecah, sember, cempreng, krasak-kresek atau bahkan hilang- timbul. sehingga tidak jelas, atau terdengarnya keras tapi tak jelas artikulasi bicaranya, atau ada gangguangangguan seperti dengung dan lain-lain yang mengganggu suara khatib. Boleh jadi, itulah anggapan umum masyarakat tentang buruknya kualitas sistem pengeras suara yang ada di sebagian besar masjid yang ada di Indonesia. Padahal, kualitas sistem pengeras suara akan sangat menentukan konsentrasi jamaah masjid yang ada di dalam masjid.

Menurut Jusuf Kala sebagai Ketua Dewan Masjid Indonesia (DMI), ada 50-75 persen dari seluruh masjid di Indonesia yang sistem pengeras suaranya tidak bagus sehingga hanya dalam jarak beberapa meter saja, sudah tidak terdengar apa yang disampaikan oleh khatib ataupun oleh muadzin. Bahkan ada beberapa yang suaranya cempreng dan membuat panggilan sholat atau khotbah ini terasa tidak merdu di telinga. (Republika, 3 Juni 2013). Hal ini karena pemasangan pengeras suara tersebut tidak fokus, ada yang menghadap kesamping kiri, kesamping kanan, dan kemanamana, sehingga suara menjadi pecah. Apalagi bila masjid yang dibangun dengan dinding marmer dan kaca, suara akan mantul, sehingga sulit untuk di dengar, akibatnya jamaah tidak bisa mendengarkan dengan maksimal.

Masjid sebagai media publik harusnya didukung oleh sistem pengeras suara yang cukup dan baik. Cukup dalam arti level suara dapat di dengar seluruh jamaah. Sedangkan baik artinya artikulasi pembicaraan dapat terbaca. Jadi baik bukan soal bassnya atau trebelnya mantab seperti pada audio musik. Penguat suara yang dibutuhkan adalah penguat yang baik untuk rentang frekuensi suara vokal baik untuk adzan, iman atau pengajian.

Untuk itulah perlu penataan atau perbaikan fasilitas masjid yang terkait dengan sistem pengeras suara. Program tersebut 
mungkin terdengar sederhana, tetapi itu sangat penting, karena 80 persen kegiatan di masjid itu adalah mendengarkan, sedangkan 10 persen sujud dan 10 persennya lagi untuk doa. Bila sistem pengeras suaranya tidak baik dan jamaah tidak bisa mendengar, maka bisa dikatakan 80 persen kegiatan di masjid menjadi sia-sia.

Ada beberapa cara menata pengeras suara tersebut diantaranya cukup mengubah letak pengeras suara menjadi satu arah sehingga murah biayanya, karena tetap menggunakan perangkat yang sudah tersedia atau tindakan lainnya. Terkait penataan sistem pengeras suara di masjid ada beberapa hal yang harus diperhatikan untuk menentukan kualitas suara yang dihasilkan. Apabila akan memasang sistem pengeras suara di masjid, langkah awal yang harus dilakukan adalah melakukan desain awal berdasarkan lebar masjid, model atap, dinding dan lantai masjid. Langkah selanjutnya adalah menyediakan peralatan yang sesuai, dan melakukan pemasangan dengan mengikuti petunjuk teknis yang ada.

Untuk menghasilkan tata suara masjid/musholla yang baik perlu perencanaan yang baik pula. Perencanaan yang baik harus dikembangkan berdasarkan kondisi real masjid dan mushola seperti luas, bentuk bangunan dan lain sebagainya. Setiap masjid/ruang adalah unik dari segi akustik, sehingga harus dicoba berbagai alternatif pemasangan speaker untuk menghasilkan kualitas suara yang optimal dan minim gangguan.

Untuk itulah perlu diberikan pelatihan penataan sistem pengeras suara masjid khususnya bagi pengurus masjid agar sistem pengeras suara masjid dapat menghasilkan suara jernih dan detil, artikulasi ucapan harus terdengar jelas. Hal ini diharapkan karena sistem pengeras suara yang terpasang nantinya bisa meminimalkan feedback yang timbul akibat mic, tidak ada noise, tidak terlalu besar level bass, suara mic tidak terdengar hanya frekuensi tinggi saja yang dihasilkan.

Mitra pada program pengabdian kepada Masyarakat ini adalah Masjid Haji Agus Salim Tunjungsekar Kota Malang. Masjid ini dibangun pada tahun 1990 dan direnovasi pada tahun 2010. Pada saat ini sistem tata suara masjid Masjid Haji Agus Salim masih belum tertata dengan baik, loud speaker sering terbakar dikarenakan kurang pahamnya takmir masjid dalam penataan sistem tata suara. Sehingga kualitas suara yang dihasilkan terutama bagi jamaah yang ada di dalam masjid dirasakan kurang baik. Untuk memperbaiki kualitas suara yang dihasilkan oleh sistem pengeras suara masjid maka perlu dilakukan pelatihan penataan dan instalasi sistem tata suara bagi para pengurus masjid Haji Agus Salim agar kualitas suara yang dihasilkan bisa lebih baik. Oleh karena itu kami team Pengabdian Masyarakat Politeknik Negeri Malang bekerja sama dengan Pengurus Masjid Haji Agus Salim sepakat akan mengadakan Pelatihan Penataan dan Instalasi Sistem Tata Suara Bagi Pengurus Masjid Haji Agus Salim.

\section{TINJAUAN PUSTAKA}

Tata suara adalah suatu teknik pengaturan peralatan suara atau bunyi pada suatu acara pertunjukan, pertemuan, rekaman dan lain lain. Tata suara memainkan peranan penting dalam suatu pertunjukan langsung dan menjadi satu bagian tak terpisahkan dari tata panggung dan bahkan acara pertunjukan itu sendiri. Tata suara erat kaitannya dengan pengaturan penguatan suara agar bisa terdengar keras tanpa mengabaikan kualitas suara-suara yang dikuatkan. Pengaturan tersebut meliputi pengaturan mikropon-mikropon, kabel-kabel, prosesor dan efek suara, serta pengaturan konsul mixer, juga audio power amplifier dan speaker-speakernya secara keseluruhan ditunjukkan dalam Gambar 1.

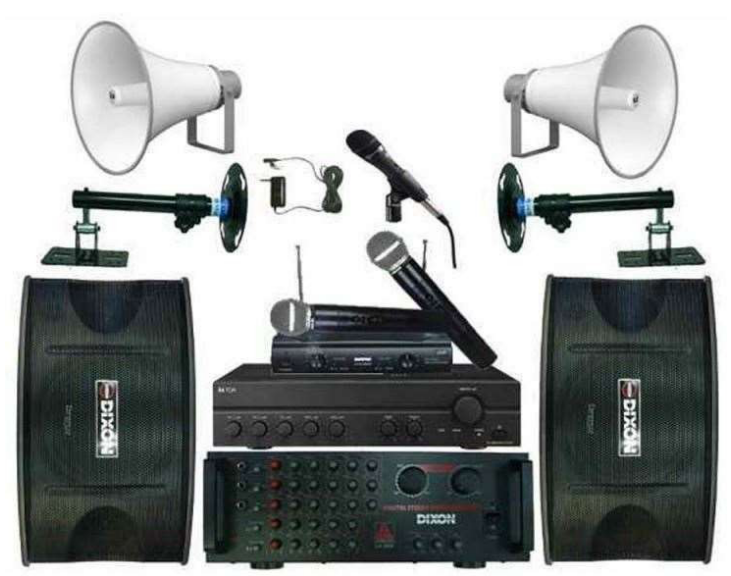

Gambar 1. Piranti elektronika untuk sistem tata suara

\subsection{Perancangan Sistem}

Pada perancangan sistem penguat suara masjid yang baik, harus dirancang sebaik mungkin. 
Desain yang baik perlu memperhatikan kondisi masjid yang akan dipasang sistem pengeras suara tersebut. Beberapa pertimbangan yang perlu diperhatikan antara lain luas area, kondisi akustik ruangan, pertimbangan penempatan untuk outdoor, input penguat suara, impedansi dan power output.

a. luas area

luas area yang akan di pasang sistem pengeras suara akan mempengaruhi kebutuhan daya yang digunakan dan proses pendistribusiannya. Penempatan beberapa speaker dengan daya yang lebih kecil dan menyebar pada titik-titik tertentu lebih baik dari pada menggunakan speaker berdaya besar tetapi hanya ditempatkan pada satu titik saja.

b. kondisi akustik ruangan

faktor kedua yaitu memperhatikan kondisi akustik ruangan. Faktor ini memerlukan trial and error di lapangan untuk bisa optimal. Pada point A perencanaan sistem disebutkan proses penempatan speaker dengan daya kecil dan ditempatkan tiap-tiap titik dalam satu ruangan tersebut. Proses penempatan titik tersebut harus mempertimbangkan beberapa hal yaitu:

- jarak antara mikrofon dan speaker jangan terlalu dekat karena bisa mengakibatkan terjadinya feedback (dengung)

- antara speaker dan mikrofon yang di pasang saling berhadapan

- apabila terpaksa antara speaker dan mikrofon saling berhadapan, diusahakan ketinggian antara speaker dan mikrofon berbeda. Idealnya posisi speaker lebih tinggi diatas ketinggian manusia dewasa ketika berdiri dan posisi arah moncong speaker harap sudut nya sedikit condong ke atas menjauhi arah mikrofon.
- Speaker yang di pasang saling berhadapan harap menukar fasa pada salah satu speaker tersebut.

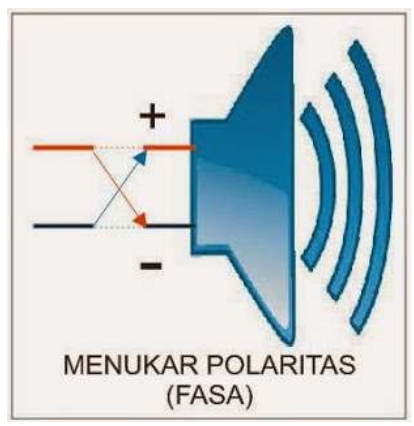

Gambar 2. Polaritas fasa

Ruangan tertutup dengan sedikit ventilasi, beratap tinggi dan mempunyai dinding tebal suara yang dihasilkan akan cenderung menggema. Maka penempatan speaker disarankan serendah mungkin atau cenderung dekat dengan audien (pendengar) dan arah speaker condong ke arah bawah.

c. Penempatan di luar ruangan

penempatan speaker dalam ruangan berbeda dengan penempatan di luar ruangan. Ada beberapa hal yang perlu diperhatikan untuk penempatan speaker di luar ruangan :

penempatan speaker yang semakin tinggi maka jangkauan speaker juga akan semakin luas, namun jika telalu tinggi maka titik yang berada di dekat masjid tidak akan terdengar.

Memperhatikan arah moncong dari speaker untuk menghadap ke bawah kurang lebih 10 derajat dari bidang datar

Memperhatikan arah moncong speaker agar tidak mengarahkan moncong ke arah bangunan yang memantulkan suara, karena akan meredam kuat suara yang dihasilkan oleh speaker.

d. Unit input

Input yang digunakan dalam hal ini adalah mikrofon. Mikrofon yang digunakan harus menggunakan mikrofon yang respon frekuensinya pada range vokal manusia. Gunakan 
mikrofon uni-directional yaitu mikrofon yang peka dalam satu arah saja. Mikrofon jenis ini menggunakan enclosure (wadah) yang di desain supaya peka terhadap suara yang datang dari depan saja.

\section{HASIL}

Hasil proses pengabdian kepada masyakarat ditunjukkan pada Gambar 3 sampai Gambar 6. Dimana Gambar 3 sampai Gambar 5 menunjukkan proses pelatihan dan penyuluhan kepada takmir masjid H Agus Salim. Gambar 6 menunjukkan hasil peletakan Speaker Masjid bagian depan.
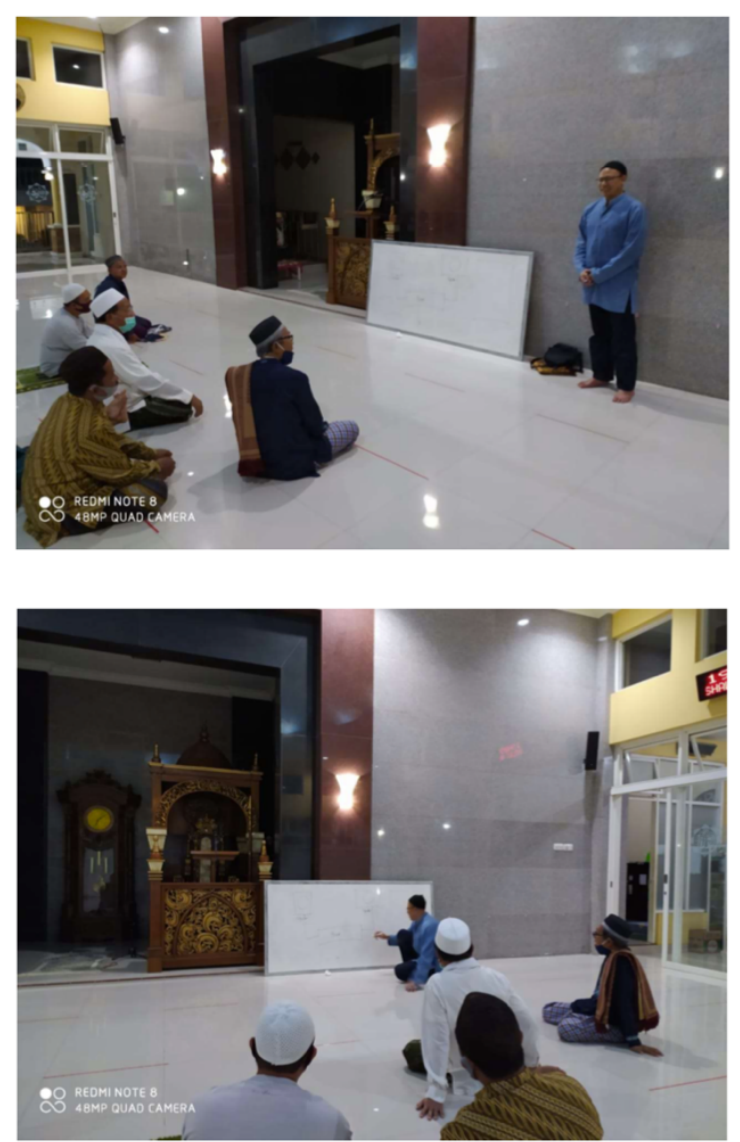
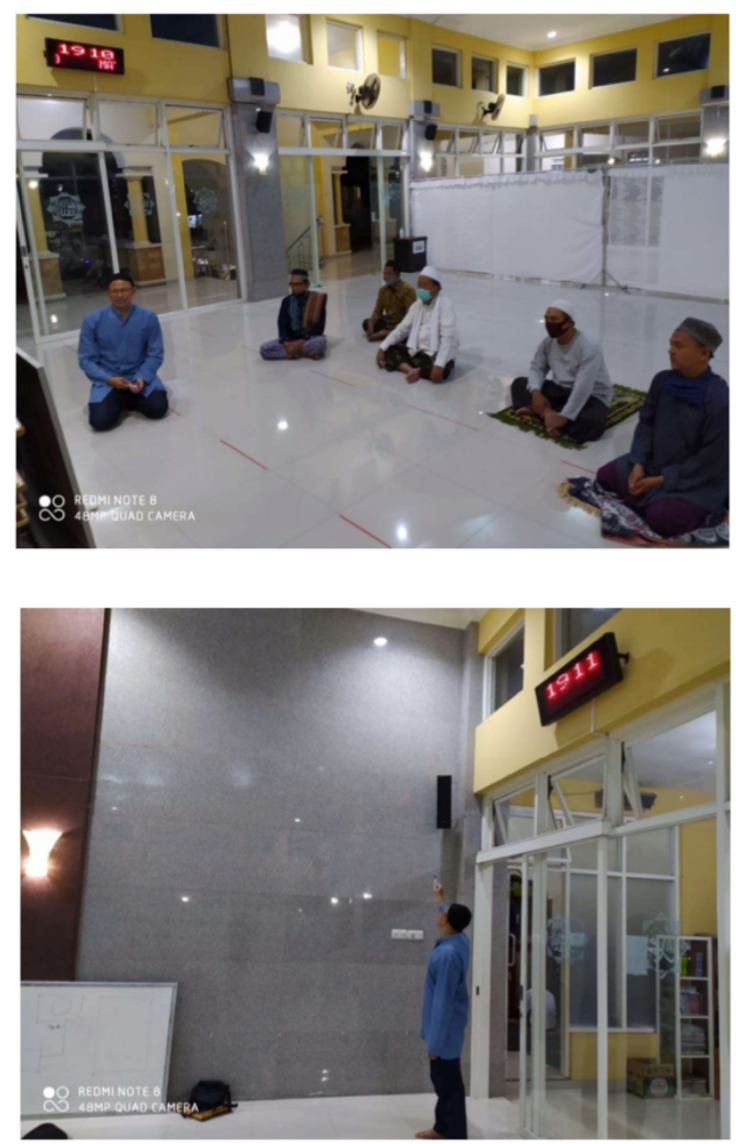

Guna mengetahui kepuasan jamaah masjid haji Agus Salim terhadap Sound Sistem yang telah terpasang di masjid maka dibuat kuesioner seperti yang ada di lampiran dengan hasil sebagai berikut:

Kuesioner dibagikan kepada 30 jamaah dengan kembali sebanyak 20 kuesiner. 20 jamaah yang memberikan jawaban kuesioner terdiri dari 13 jamaah laki-laki dan 7 jamaah perempuan dengan usia kurang dari 30 tahun sebanyak 5 jamaah, usia antara 30 sampai 50 tahun sebanyak 7 jamaah, dan usia lebih dari 50 tahun sebanyak 8 jamaah. Hasil kuesioner ditunjukkan dalam Tabel 4.1.

Tabel 1. Hasil Kuesioner Kepuasan Jamaah Masjid Haji Agus Salim terhadap Sound Sistem Masjid

\begin{tabular}{|l|l|l|l|l|l|l|l|}
\hline $\begin{array}{l}\text { Respon } \\
\text { den }\end{array}$ & P1 & P2 & P3 & P4 & P5 & $\begin{array}{l}\text { Juml } \\
\text { ah }\end{array}$ & $\begin{array}{l}\text { Rat } \\
\text { a- } \\
\text { rat } \\
\text { a }\end{array}$ \\
\hline 1 & 4 & 5 & 4 & 5 & 5 & 23 & 4,6 \\
\hline 2 & 4 & 4 & 5 & 5 & 5 & 23 & 4,6 \\
\hline 3 & 5 & 5 & 5 & 4 & 4 & 23 & 4,6 \\
\hline
\end{tabular}




\begin{tabular}{|l|l|l|l|l|l|l|l|}
\hline 4 & 4 & 4 & 4 & 4 & 4 & 20 & 4 \\
\hline 5 & 5 & 5 & 4 & 4 & 4 & 22 & 4,4 \\
\hline 6 & 4 & 4 & 5 & 5 & 5 & 23 & 4,6 \\
\hline 7 & 5 & 5 & 5 & 4 & 4 & 23 & 4,6 \\
\hline 8 & 5 & 4 & 5 & 4 & 4 & 22 & 4,4 \\
\hline 10 & 4 & 4 & 4 & 4 & 5 & 21 & 4,2 \\
\hline 11 & 4 & 4 & 4 & 4 & 4 & 19 & 4 \\
\hline 12 & 4 & 5 & 5 & 5 & 5 & 24 & 4,8 \\
\hline 13 & 5 & 4 & 4 & 4 & 4 & 21 & 4,2 \\
\hline 14 & 5 & 4 & 5 & 5 & 5 & 24 & 4,8 \\
\hline 15 & 5 & 4 & 4 & 4 & 5 & 22 & 4,4 \\
\hline 16 & 5 & 5 & 4 & 4 & 5 & 23 & 4,6 \\
\hline 17 & 5 & 4 & 4 & 4 & 5 & 22 & 4,4 \\
\hline 18 & 5 & 4 & 4 & 4 & 4 & 21 & 4,2 \\
\hline 19 & 4 & 4 & 4 & 4 & 5 & 21 & 4,2 \\
\hline 20 & 5 & 4 & 4 & 4 & 5 & 22 & 4,4 \\
\hline Jumlah & 92 & 86 & 87 & 85 & 91 & & \\
\hline $\begin{array}{l}\text { Rata- } \\
\text { rata }\end{array}$ & 4,6 & 4,3 & 4,35 & 4,2 & 4,5 & & \\
5 & & & 5 & & \\
\hline
\end{tabular}

http://www.teknikaudiovideo.com/2013/ $\underline{01 / \text { instalasi-sound-system.html }}$

Republika, 2013. Ribuan Masjid di Indonesia tak punya peralatan sound system yang mumpuni. Edisi Senin, 03 Juni 2013. www. REPUBLIKA.co.id

Subiyantoro, 2000. Seri Diktat Kuliah Telekomunikasi dan Komputer. Jakarta : Penerbit Gunadarma

Dari tabel 1 menunjukkan bahwa jamaah masjid haji Agus Salim merasa puas dengan suara yang dihasilkan dari sound sistem yang sekarang ini terpasang di masjid. Hal ini menunjukkan bahwa pelatihan penataan dan instalasi dan tata suara di masjid haji agus salim berhasil dengan baik.

\section{KESIMPULAN}

Berdasarkan pengabdian kepada masyarakat yang telah dilakukan maka dapat diambil kesimpulan sebagai berikut:

1. Jamaah masjid haji Agus salim sangat puas dengan tata suara di masjid haji agus salim dengan nilai diatas 4 dalam skala 5 .

2. Pelatihan penataan dan instalasi tata suara di masjid haji agus salim berhasil dengan baik.

\section{DAFTAR PUSTAKA}

http://www.mawarbiru.net/2012/08/12/installa si-sound-system-di-masjid-bagian-1/

http://tekno.kompas.com/read/2009/08/2 8/15231025/bikin.sound.system.masjid. enggak.lagi.sem ber.cempreng.dan.krasak-kresek 